\title{
Naphthalenediimide/Formamidinium-Based Low-Dimensional Perovskites
}

\author{
Aditya Mishra ${ }^{\not+\#}$, Paramvir Ahlawat ${ }^{\dagger, \#}$, George C. Fish ${ }^{\sharp, \#}$, Farzaneh Jahanbakhshi ${ }^{\dagger, \#}$, Marko \\ Mladenovićt, Masaud Almalki ${ }^{\S}$, Marco A. Ruiz-Preciado, ${ }^{\S}$, María C. Gelvéz-Rueda ${ }^{q}$, \\ Dominik J. Kubicki ${ }^{\S, t}$, Pascal A. Schouwink ${ }^{\dagger}$, Vincent Dufoulon ${ }^{\S}$, Thomas Schneeberger ${ }^{\S}$, Artin \\ Aslanzadeh", Ferdinand C. Grozema ${ }^{q}$, Shaik M. Zakeeruddin ${ }^{\S}$, Jacques-Edouard Moser"t, Ursula \\ Rothlisberger ${ }^{\dagger, *}$, Lyndon Emsley ${ }^{t, *}$, Jovana V. Milićc, ${ }^{\xi, *}$, and Michael Grätzel ${ }^{\xi, *}$ \\ "These authors contributed equally \\ ${ }^{\ddagger}$ Laboratory of Magnetic Resonance, École Polytechnique Fédéralé de Lausanne, Switzerland; \\ ${ }^{\dagger}$ Laboratory of Computational Chemistry and Biochemistry, École Polytechnique Fédéralé de Lausanne, \\ Switzerland; ${ }^{\S}$ Laboratory of Photonics and Interfaces, École Polytechnique Fédéralé de Lausanne, \\ Switzerland; ${ }^{8}$ Department of Chemical Engineering, Delft University of Technology, The Netherlands; \\ \#Photochemical Dynamics Group, École Polytechnique Fédéralé de Lausanne, Switzerland; ${ }^{\dagger}$ X-ray \\ Diffraction and Surface Analytics, École Polytechnique Fédéralé de Lausanne, Switzerland; ${ }^{\circledR}$ Adolphe \\ Merkle Institute, University of Fribourg, Switzerland. *Correspondence: ursula.roethlisberger@epfl.ch; \\ 1yndon.emsley@epfl.ch; jovana.milic@unifr.ch; michael.graetzel@epfl.ch
}

\section{Table of Contents}

S1. Materials and Methods 2

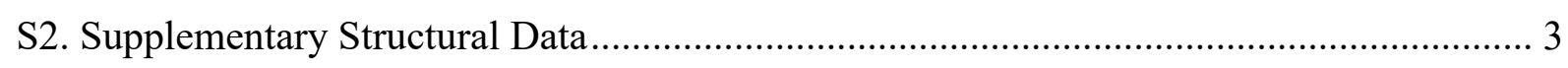

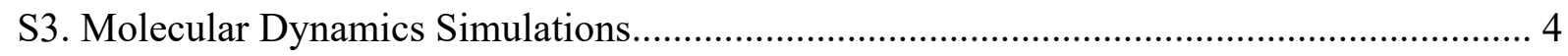

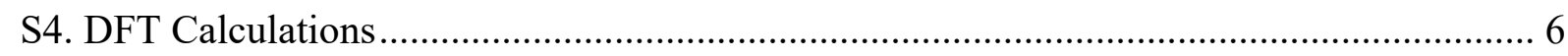

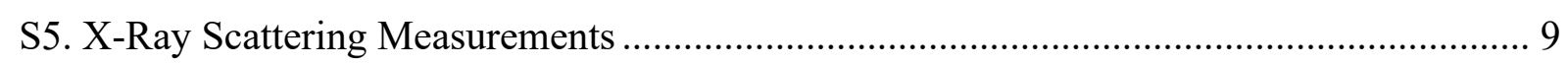

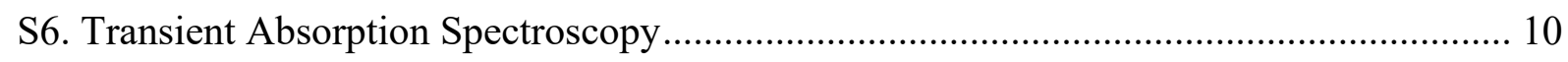

S7. Time Resolved Microwave Conductivity Measurements............................................... 11

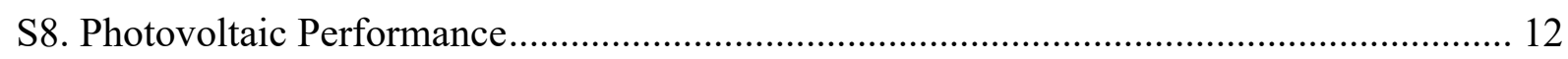

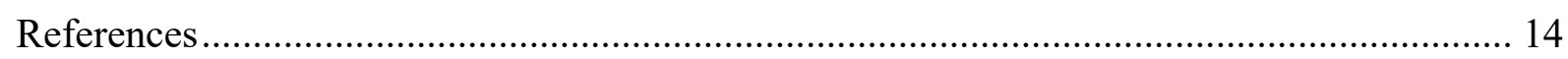

Data presented here can be accessed at DOI:10.5281/zenodo.5172265 and it is available under the license CC-BY-4.0 (Creative Commons Attribution-ShareAlike 4.0 International) or from the corresponding authors upon request. 


\section{S1. Materials and Methods}

Spacer 2,2'-(1,3,6,8-tetraoxo-1,3,6,8-tetrahydrobenzo[lmn][3,8]phenanthroline-2,7-diyl)bis(ethan-1aminium) (NDIAI 2 synthesis: Boc-protected ethylene diamine $(1.5 \mathrm{~mL}, 37 \mathrm{mmol})$ was added to a suspension of NDI anhydride (1.00 g, $3.73 \mathrm{mmol})$ in DMF $(30 \mathrm{~mL})$. The mixture was stirred for $15 \mathrm{~h}$ at $75^{\circ} \mathrm{C}$ and the product was extracted by $\mathrm{CH}_{2} \mathrm{Cl}_{2}$, dried over ang. $\mathrm{MgSO}_{4}$ and concentrated under vacuum. Dry flash chromatography $\left(\mathrm{SiO}_{2}, \mathrm{CH}_{2} \mathrm{Cl}_{2} / \mathrm{CH}_{2} \mathrm{OH}\right.$ 9:1) yielded di-tert-butyl ((1,3,6,8-tetraoxo-1,3,6,8tetrahydrobenzo[lmn][3,8]phenanthroline-2,7-diyl)bis(ethane-2,1-diyl))dicarbamate

(NDIEAB) intermediate $(1.7 \mathrm{~g}, 83 \%)$ as an orange solid. HI (1.67 mL, $12.6 \mathrm{mmol}, 57 \%)$ was added to a suspension of the intermediate $(1.7 \mathrm{~g}, 3.08 \mathrm{mmol})$ in $\mathrm{EtOH}(15 \mathrm{~mL})$ at $0{ }^{\circ} \mathrm{C}$. The mixture was stirred for $12 \mathrm{~h}$ and the solution concentrated, resuspended in diethyl ether $(10 \mathrm{~mL})$, filtered, washed with diethyl ether and isopropanol, and vacuum-dried to yield $\mathrm{NDIEAI}_{2}(0.7 \mathrm{~g}, 75 \%)$ as a yellow solid. ${ }^{1} \mathrm{H}$ NMR $(400 \mathrm{MHz}$, $\left.\left(\mathrm{CD}_{3}\right)_{2} \mathrm{SO}\right): \delta=8.74(\mathrm{~s}, 4 \mathrm{H}), 7.81(\mathrm{~s}, 6 \mathrm{H}), 4.35(\mathrm{t}, J=5.9 \mathrm{~Hz}, 4 \mathrm{H}), 3.20(\mathrm{q}, J=5.9 \mathrm{~Hz}, 4 \mathrm{H}) \mathrm{ppm} ;{ }^{13} \mathrm{C}$ NMR $\left(101 \mathrm{MHz},\left(\mathrm{CD}_{3}\right)_{2} \mathrm{SO}\right): \delta=163.73,130.88,127.06,126.68,38.35,37.98$ ppm; HRMS (ESI+/QTOF): $m / z(\%) 353.1241\left(100,[M]^{+}\right.$, calcd for $\left.\mathrm{C}_{18} \mathrm{H}_{17} \mathrm{~N}_{4} \mathrm{O}_{4}{ }^{+}: 353.1244\right)$; (ESI-/QTOF): $m / z(\%)$ $126.9055\left(100,[M]^{-}\right.$, calcd for $\left.I^{-}: 126.9050\right)$.

Perovskite mechanosynthesis: Perovskite powders were synthesized by grinding the reactants in an electric ball mill (Retsch Ball Mill MM-200) using a grinding jar $(10 \mathrm{ml})$ and a ball $(\varnothing 10 \mathrm{~mm})$ for $30 \mathrm{~min}$ at $25 \mathrm{~Hz}$ in accordance with the previously reported procedure. ${ }^{[1-2]}$ The amounts of reagents taken into the synthesis were determined by the reported stoichiometry. The resulting powders were annealed at $150{ }^{\circ} \mathrm{C}$ for $15 \mathrm{~min}$ to reproduce the thin-film synthetic procedure.

Thin film preparation: Films were fabricated through a stepwise preparation process. The substrates were cleaned with oxygen plasma for $15 \mathrm{~min}$. The precursor solution of the (NDIEA)FA $A_{n-1} \mathrm{~Pb}_{n} \mathrm{I}_{3 \mathrm{n}+1}$ (NDIEA = 2,2'-(1,3,6,8-tetraoxo-1,3,6,8-tetra-hydrobenzo[1mn][3,8]phenanthroline-2,7-diyl)bis(ethan1-aminium)) layered perovskite films $(\langle n\rangle=1,2,3)$ of the defined concentration $(0.4-0.6 \mathrm{M})$ was prepared by dissolving the stoichiometric quantities of $\mathrm{PbI}_{2}, \mathrm{FAI}$, and NDIEA 2 in the solvent mixture comprised of dimethylformamide (DMF) and dimethylsulfoxide (DMSO) with the volume ratio of 4:1. The perovskite film was deposited by spin-coating onto the substrate. The spin-coating procedure was performed in a glovebox under inert nitrogen atmosphere by a consecutive two-step spin-coating process at first $1000 \mathrm{rpm}$ for $10 \mathrm{~s}$ with a ramp of $200 \mathrm{rpm} \mathrm{s}^{-1}$ and second $4000 \mathrm{rpm}$ for $20 \mathrm{~s}$ with a ramp of $2000 \mathrm{rpm} \mathrm{s}^{-1}$. Subsequently, the substrate was annealed at $150^{\circ} \mathrm{C}$ for $15 \mathrm{~min}^{[1]}$

UV-Vis absorption measurements were recorded using Varian Cary5 UV-visible spectrophotometer.

Steady-state photoluminescence (PL) spectra were recorded by exciting the layered perovskite films deposited onto microscope glass. The emission between $460-830 \mathrm{~nm}$ was recorded with a Fluorolog 322 spectrometer (Horiba Jobin Yvon iHr320 and a CCD) within with a bandpass of $5 \mathrm{~nm}$ upon 
excitation at $420 \mathrm{~nm}$ with a band pass of $5 \mathrm{~nm}$. The samples were mounted at $60^{\circ}$ and emission recorded at $90^{\circ}$ from the incident beam path.

X-ray diffraction $(X R D)$ patterns were recorded on an X'Pert MPD PRO (PANanalytical) equipped with a ceramic tube providing Ni-filtered ( $\mathrm{Cu}$ anode, $\lambda=1.54060 \AA$ ) radiation and a RTMS X'Celerator (PANalytical). The measurements were done in BRAGG-BRENTANO geometry. The samples were mounted without further modification and the automatic divergence slit $(10 \mathrm{~mm})$ and beam mask (10 $\mathrm{mm}$ ) were adjusted to the dimension of the films.

\section{S2. Supplementary NMR Data}
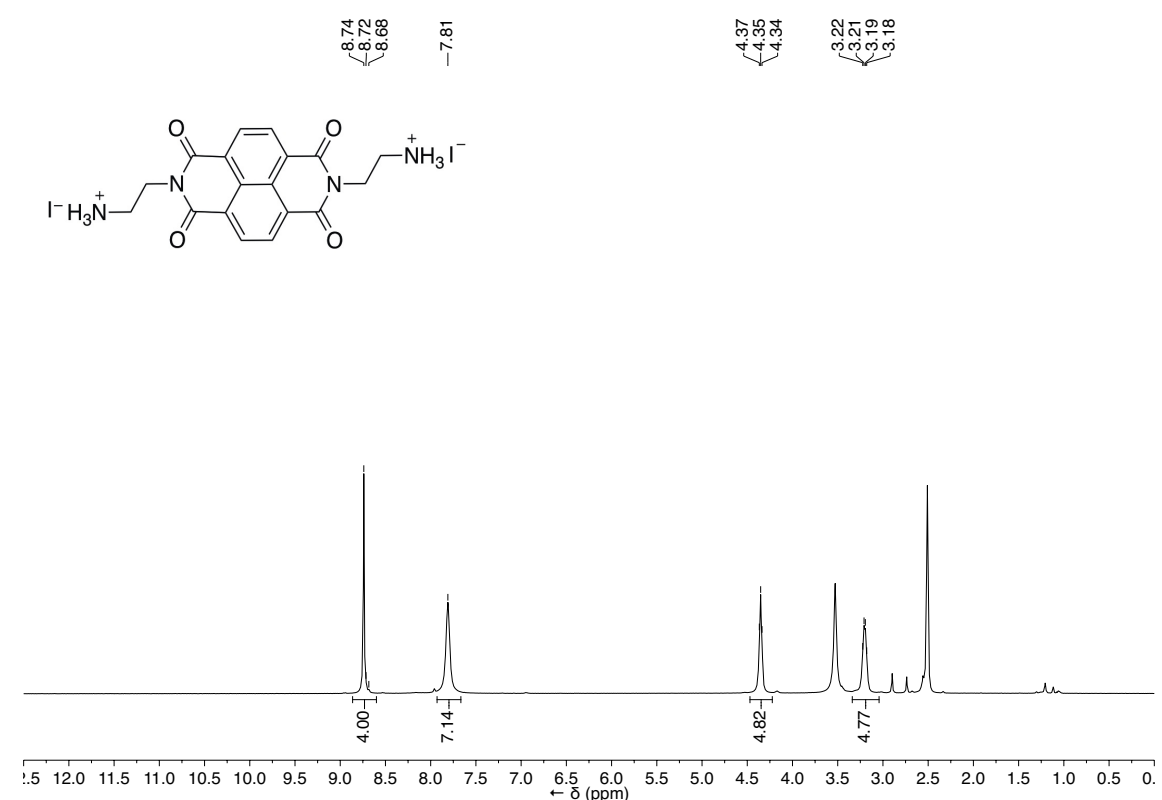

Figure S1. ${ }^{1} \mathrm{H}$ NMR of NDIEAI 2 in $\left(\mathrm{CD}_{3}\right)_{2} \mathrm{SO}(400 \mathrm{MHz}, 298 \mathrm{~K})$
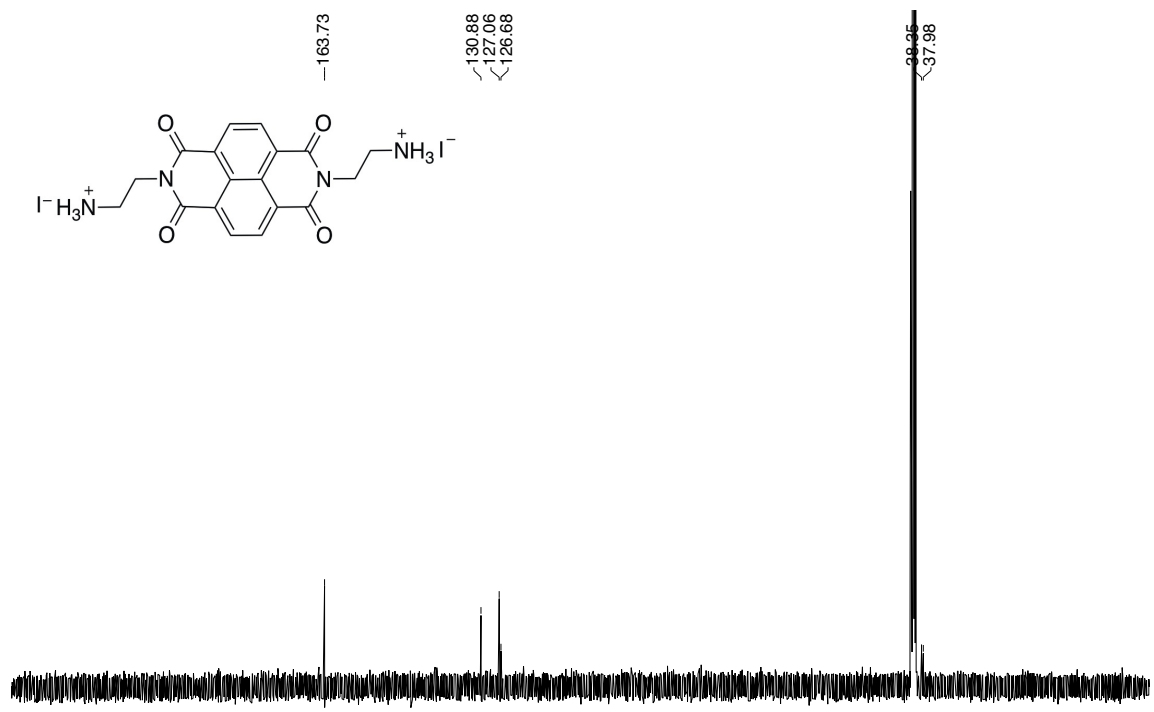

$\begin{array}{lllllllllllllllllllllll}220 & 210 & 200 & 190 & 180 & 170 & 160 & 150 & 140 & 130 & 120 & 110 & 100 & 90 & 80 & 70 & 60 & 50 & 40 & 30 & 20 & 10 & 0\end{array}$

Figure S2. ${ }^{13} \mathrm{C}$ NMR of NDIEAI 2 in $\left(\mathrm{CD}_{3}\right)_{2} \mathrm{SO}(101 \mathrm{MHz}, 298 \mathrm{~K})$ 


\section{S3. Molecular Dynamics Simulations}

\section{S3.1. MD Methods}

The initial structures were built with VMD by placing the ligands between layers of $\mathrm{Pb}-\mathrm{I}$ octahedra. $\mathrm{A}$ fixed-point charge interatomic potential was chosen for $\mathrm{Pb}$ and I from the available literature. ${ }^{[6]}$ We have selected this force field as it is known to represent the crystal structures of both $\mathrm{PbI}_{2}$ and perovskites. The Generalized Amber Force Field (GAFF) was used to parameterize the ligand and formamidinium ions. The force field files are available upon request from the corresponding author. We have chosen a $1.0 \mathrm{~nm}$ cutoff for nonbonded interactions and three-dimensional periodic boundary conditions were applied for each simulation. Long-range electrostatic interactions were treated with the particle-particleparticle-mesh Ewald method. We employed the SHAKE algorithm ${ }^{[7]}$ to constrain the bond length of hydrogen atoms. The time step used in all of the simulations was $2 \mathrm{fs}$. The simulations were performed with the Large-scale Atomic/Molecular Massively Parallel Simulator (LAMMPS) code. ${ }^{[8]}$ The systems were first minimized with a conjugate gradient algorithm with a tolerance of maximum residual force of $10^{-3} \mathrm{kcal} / \mathrm{molA}$. After minimization, the systems were relaxed with an equilibrium run which was carried out in the isothermal-isobaric ensemble. We used a velocity rescaling thermostat with a relaxation time of 0.1 ps. $^{[9]}$ The Parrinello-Rahman barostat ${ }^{[10]}$ was used to keep the pressure equal to the standard atmospheric pressure. The relaxation time of the barostat was set to $10 \mathrm{ps}$. We use the triclinic variable cell barostat in all of our simulations. With this setup, the temperature was slowly increased from $0 \mathrm{~K}$ to $\mathrm{T}$ (specified temperature) in $10 \mathrm{~ns}$. We then performed $30 \mathrm{~ns}$ simulations at the constant temperature. The resulting structures obtained by MD simulations were further used as input structures for DFT optimizations (Section S4).

\section{S3.2. Structure Analysis}

Predicting crystal structures of mixed organic-inorganic multi-component perovskites is a complex problem. In particular, the high level of complexity in this case stems from the larger size and multifunctional structure of the spacer molecules, which can have multiple bonding arrangements. To simplify the problem, we limited our study to the 2D perovskite space. We started initially from a smaller supercell with Dion-Jacobson structure by placing NDIEA molecules between layers of corner-sharing $\mathrm{Pb}-\mathrm{I}$ octahedra and follow a similar protocol as in our previous studies. ${ }^{[6]}$ The structural evolution from the initial guess to the final (lowest-energy equilibrated structure) is shown in the Supplementary movie. We obtain stable 2D-perovskite structures for $n=1-4$ composition from classical MD that were subsequently relaxed at the DFT level (Figure S3). 
a

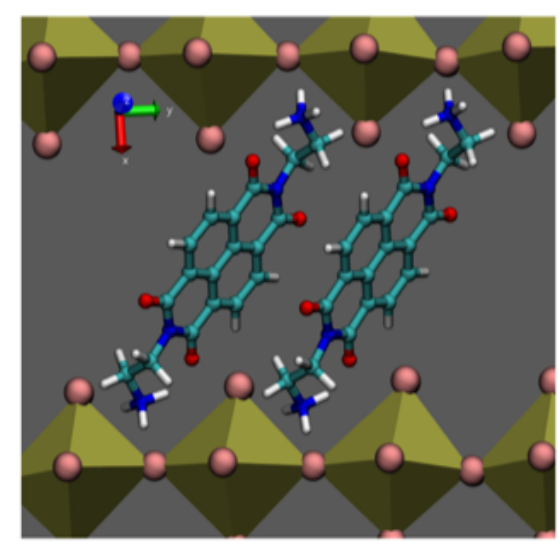

C

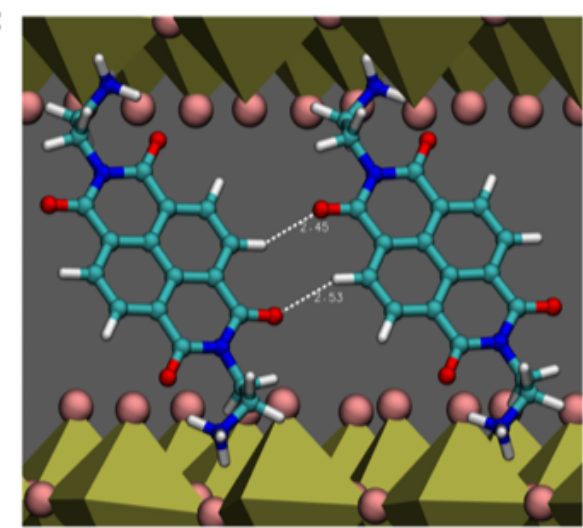

e
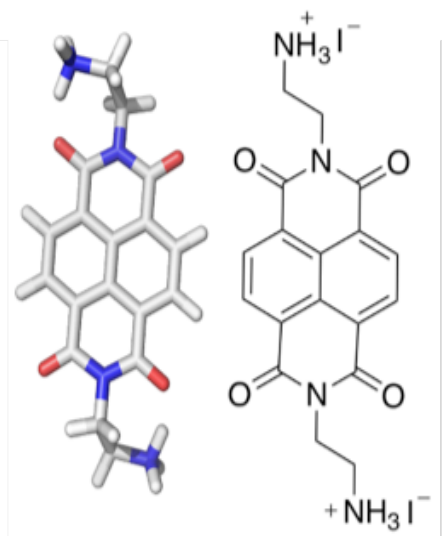

b

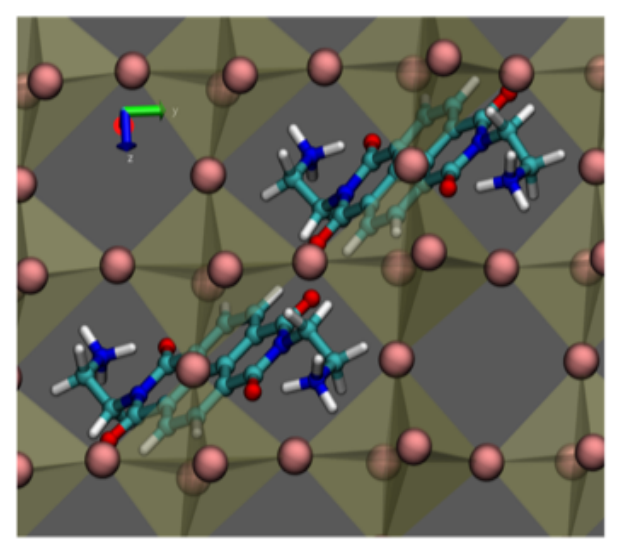

d

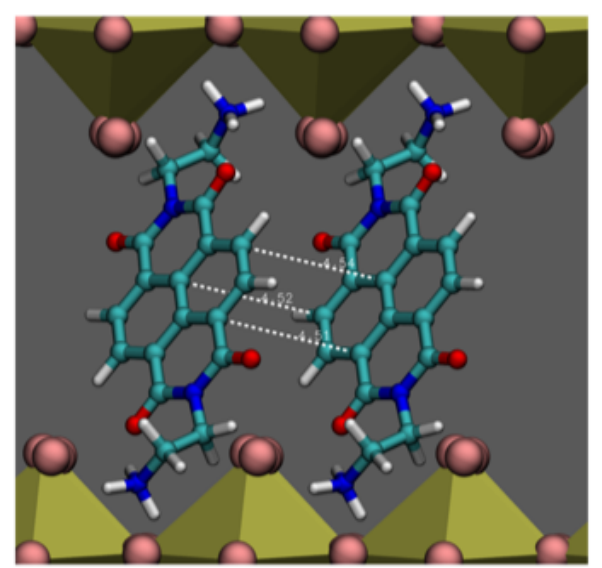

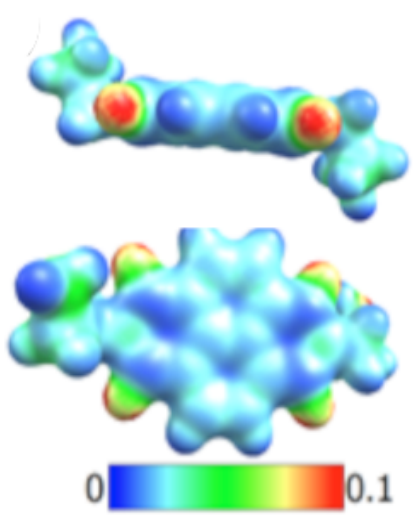

Figure S3. Structural analysis for 2D-NDIEA based perovskites. (a) Side view of the equilibrated geometry for $n=1$ composition. (b) Inter-ligand arrangement. NDIEA molecules interact via (c) hydrogen bonding and (d) $\pi-\pi$ interactions. Only two NDIEA molecules are represented for the sake of clarity. The images are generated with VMD. $\mathrm{Pb}-\mathrm{I}$ octahedra are shown with golden color, iodide anions are depicted with orange spheres, whereas NDIEA molecules are shown with balls-and-sticks models: carbon is shown in light blue, nitrogen in dark blue, oxygen as red and hydrogen atoms in white. (e) Electrostatic potential surface map of unprotonated NDIEA spacer groups along with the corresponding structure and optimized geometry (DFT B3LYP/6-21G(d)) with a relative charge scale. 


\section{S4. DFT Calculations}

\section{S4.1. DFT Methods}

$\mathrm{Ab}$ initio calculations based on the Generalized Gradient Approximation (GGA) of Density Functional Theory (DFT) were performed using the Quantum Espresso code. ${ }^{[11]}$ The PerdewBurke-Ernzerhof functional revised for solids (PBEsol) ${ }^{[12]}$ was chosen based on benchmarks on $2 \mathrm{D}$ perovskites of AVA-MA ${ }^{[13 \mathrm{a}]}$ and AVA-FA ${ }^{[14]}$ where a good description of the electronic and structural properties was achieved with this functional. Valence-core electron interactions were taking into account using ultra-soft pseudopotentials in combination with a plane wave basis set up to kinetic energy cutoffs of $60 \mathrm{Ry}$ and $350 \mathrm{Ry}$ for the wavefunction and for the density, respectively. The Brillouin zone was sampled by $2 \times 2 \times 4$ and $1 \times 2 \times 4$ k-point grids for $n=1,2$ and $n=3$, respectively. The Coulomb-Attenuation Method (CAM) in the form of the CAM-B3LYP functional ${ }^{[15]}$ was employed for calculation of the band gaps to reliably predict charge-transfer excitations with low orbital overlap, taking also the spin-orbit coupling (SOC) effects into account, which are calculated at the GGA level. For this, norm-conserving pseudopotentials were used with a plane wave basis set of 80 Ry kinetic energy cutoff for the wavefunctions. To verify the nature of the band edges, projected density of states for the frontier orbitals were obtained at the PBE0 level. ${ }^{[16]}$ Eventually, to compare the charge transfer features of these systems with other $2 \mathrm{D}$ and 2D/3D systems, effective masses of the charge carriers were determined via numerical differentiation of the band structures. ${ }^{[13 \mathrm{~b}]}$

\section{S4.2. Structural Analysis}

The structures were initially obtained by classical molecular dynamics simulations, equilibrated at the force-field level and later optimized at DFT level. Due to the bifunctional nature of NDIEA ligands, an initial Dion-Jacobson (DJ) phase was adopted and maintained in the final DFT-optimized structures (as depicted in Figure S4).

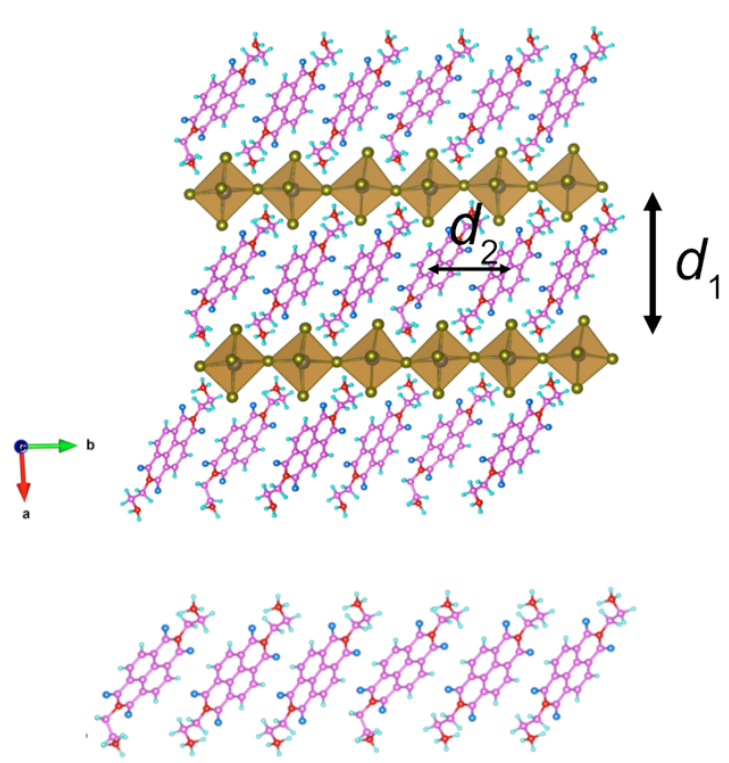


Table S1. Characteristic structural features of (NDIEA)FA $A_{n-1} \mathrm{~Pb}_{n} \mathrm{I}_{3 \mathrm{n}+1}$ for $n=1-3$. Octahedral tilting angles were measured with respect to two in-plane and one out-of-plane directions. Distances are given in angstrom. Angles of octahedral tilting, tilting of the aromatic planes with respect to the perovskite layer and corresponding standard deviations are in degrees.

\begin{tabular}{|c|c|c|c|c|c|}
\hline$n$ & Octahedral Tilting $\left(^{\circ}\right)$ & $\mathbf{N} \cdots \mathbf{P b}(\AA)$ & $d_{1}(\AA)$ & $\mathbf{d}_{2}(\AA)$ & Spacer Tilting $\left(^{\circ}\right)$ \\
\hline 1 & $\begin{array}{l}90.85 \pm 8.13 \\
88.09 \pm 4.96\end{array}$ & 2.9 & 16.3 & 6.4 & $43.6 \pm 1.9$ \\
\hline 2 & $\begin{array}{l}90.6 \pm 4.3 \\
88.8 \pm 4.0 \\
83.3 \pm 2.7\end{array}$ & 2.7 & 15.6 & 6.4 & $48.1 \pm 3.1$ \\
\hline 3 & $\begin{array}{l}89.8 \pm 4.8 \\
89.5 \pm 5.0 \\
88.0 \pm 3.3\end{array}$ & 2.5 & 16.2 & 6.3 & $47.7 \pm 0.2$ \\
\hline
\end{tabular}

\section{S4.3. Electronic Properties}

The band gaps for the optimized (NDIEA)FA $A_{n-1} \mathrm{~Pb}_{n} \mathrm{I}_{3 \mathrm{n}+1}$ structures were calculated at the CAMB3LYP level including SOC effects. The calculated band gap for (NDIEA)PbI 4 is $2.37 \mathrm{eV}$, which is in good agreement with the measured optical gap $(2.0 \mathrm{eV}$; Table S1), given that the excitonic effects are not included in the calculations. In comparison to the band gaps of the (PDMA)FAn-1 $\mathrm{Pb}_{n} \mathrm{I}_{3 \mathrm{n}+1}$ systems or other $2 \mathrm{D}$ perovskites, ${ }^{[17]}$ the band gap is systematically lower in the case of NDIEA spacers. ${ }^{[18,19]}$ This is the result of two effects: (1) The bottom of the conduction band (BCB) is localized on the NDIEA molecules, which leads to a significant lowering of the conduction band with respect to that in the PDMA-based or other systems with electro-inactive spacers, ${ }^{[17]}$ and (2) the structures of the inorganic slabs are more cubic, which enhances orbital overlap and destabilizes the top of the valence band (TVB). ${ }^{[20]}$ The NDIEA spacers adopt a preferred conformation, which remains essentially unchanged during 5 ps of ab-initio molecular dynamics simulations at finite temperatures of $200 \mathrm{~K}, 300 \mathrm{~K}$ and $400 \mathrm{~K}$. The hole effective masses in the in-plane directions (Table S2) decrease as expected upon increasing $\mathrm{n}$ while significantly larger hole and electron masses are found for the direction perpendicular to the inorganic layer. In general, the in-plane hole effective masses are of the same order of magnitude as those of the other 2D perovskites, such as the PDMA-based structures. ${ }^{[17]}$ However, the same behavior is not observed for the electron effective masses as the $\mathrm{BCB}$ is localized on the NDIEA molecules. 
Table S2. Calculated band gaps at CAM-B3LYP+SOC level together with hole $\left(\mathrm{m}_{\mathrm{h}}\right)$ and electron $\left(\mathrm{m}_{\mathrm{e}}\right)$ effective masses of (NDIEA)FA $A_{n-1} \mathrm{~Pb}_{\mathrm{n}} \mathrm{I}_{3 \mathrm{n}+1}$ for $n=1,2$ and 3 calculated at the GGA level. The available experimental values are indicated with an asterisk. Analogous effective masses for PDMA-based systems are indicated with \#.

\begin{tabular}{|c|c|c|c|c|c|c|c|}
\hline $\boldsymbol{n}$ & Band gap (eV) & $\mathbf{m}_{\mathbf{h}, \mathbf{x x}}$ & $\mathbf{m}_{\mathbf{h}, \mathbf{y y}}$ & $\mathbf{m}_{\mathbf{h}, \mathbf{z z}}$ & $\mathbf{m}_{\mathbf{e}, \mathbf{x x}}$ & $\mathbf{m}_{\mathbf{e}, \mathbf{y y}}$ & $\mathbf{m}_{\mathbf{e}, \mathbf{z z}}$ \\
\hline 1 & $2.37,2.0^{*}$ & $0.27,0.30^{\#}$ & $0.62,0.34^{\#}$ & Large & $6.7,0.31^{\#}$ & $90.0,0.38^{\#}$ & Large \\
\hline 2 & $1.75,1.6^{*}$ & $0.18,0.29^{\#}$ & $0.29,0.32^{\#}$ & Large & $3.4,0.12^{\#}$ & $14.8,0.81^{\#}$ & Large \\
\hline 3 & 1.74 & $0.18,0.21^{\#}$ & $0.23,0.24^{\#}$ & Large & $5.3,0.12^{\#}$ & $12.1,1.18^{\#}$ & Large \\
\hline
\end{tabular}

Partial densities of states (Figure S5, a-c) indicate a contribution from the organic part to the band edges for $n=1,2$ and 3 perovskite compositions. Furthermore, frontier molecular orbitals (Figure S5, $\mathrm{d}-\mathrm{f}$ ) indicate localization of the BCB and higher states on the ligand, while the TVB is delocalized over the inorganic part.
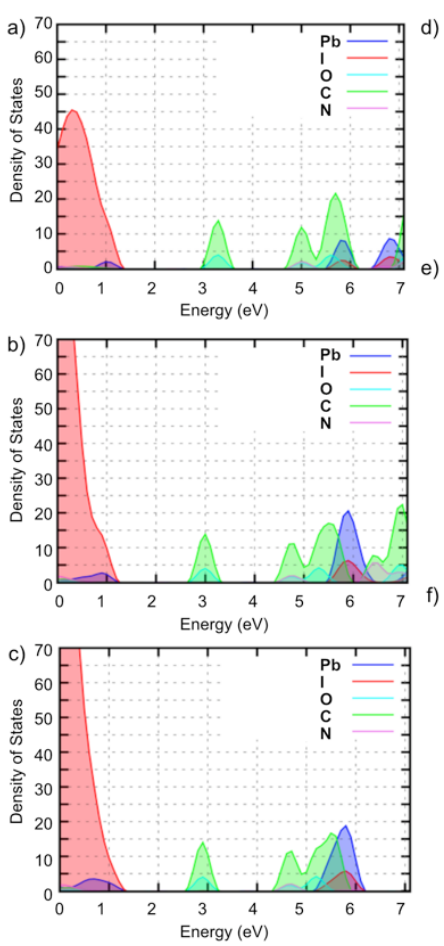
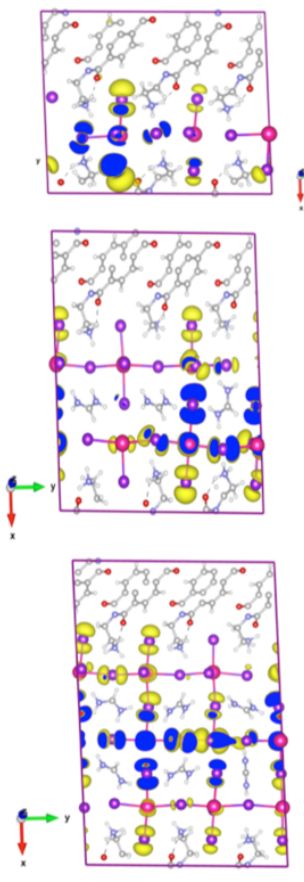
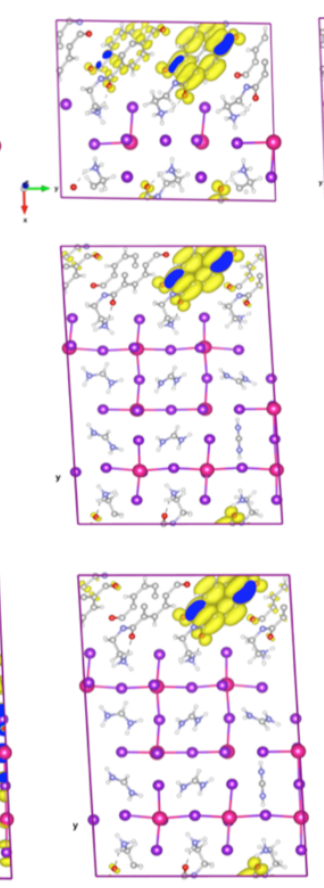
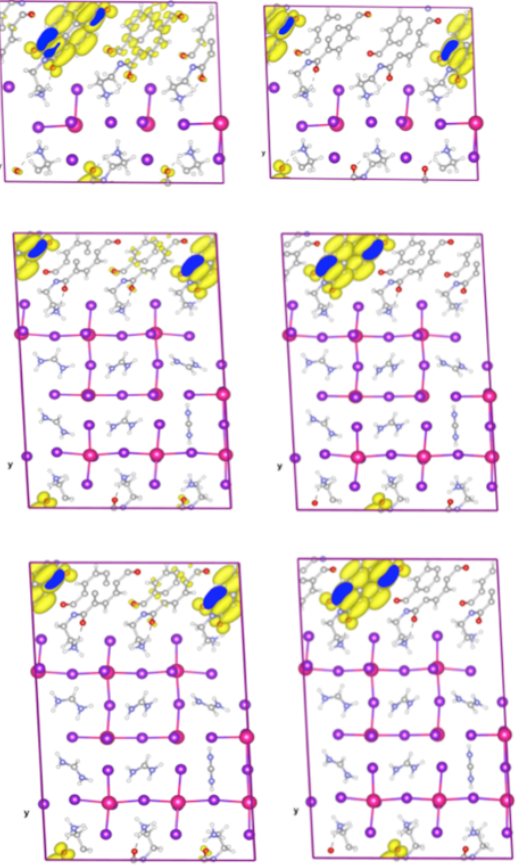

Figure S5. $(\mathrm{a}-\mathrm{c})$ Calculated partial densities of states at the PBE0 level of theory for (NDIEA)FA $\mathrm{A}_{\mathrm{n}}$ ${ }_{1} \mathrm{~Pb}_{\mathrm{n}} \mathrm{I}_{3 \mathrm{n}+1}$, (a) $n=1$, (b) $n=2$, and (c) $n=3$ compositions. (d-f) Frontier molecular orbitals (HOMO, LUMO, LUMO+1 and LUMO+2) at PBE0 level for (NDIEA)FA ${ }_{n-1} \mathrm{~Pb}_{n} \mathrm{I}_{3 \mathrm{n}+1}$ (d) $n=1$, (e) $n=2$ and (f) $n$ $=3$ compositions. $(\mathrm{d}-\mathrm{f})$ Frontier molecular orbitals $(\mathrm{HOMO}, \mathrm{LUMO}, \mathrm{LUMO}+1$ and $\mathrm{LUMO}+2)$ at PBE0 level for (NDIEA)FA $A_{n-1} \mathrm{~Pb}_{n} \mathrm{I}_{3 \mathrm{n}+1}$ (d) $n=1$, (e) $n=2$ and (f) $n=3$ compositions. 


\section{S5. X-Ray Scattering Measurements}

\section{S5.1. Methods}

Grazing incidence wide angle X-ray scattering of (NDIEA)FA $\mathrm{An}_{n-1} \mathrm{~Pb}_{n} \mathrm{I}_{3 n+1}$ thin films on glass slides was measured at $2^{\circ}$ incidence angle with a D8 Discover Plus TXS (Bruker) equipped with rotating anode $(\mathrm{Cu})$, a Dectris Eiger2 2D detector, and using a point-collimated beam of approx. $300 \mu \mathrm{m}$, at a power of $5.4 \mathrm{~kW}$.

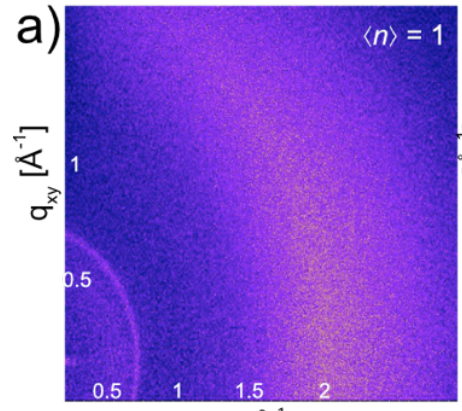

$q_{2}\left[\AA^{-1}\right]$

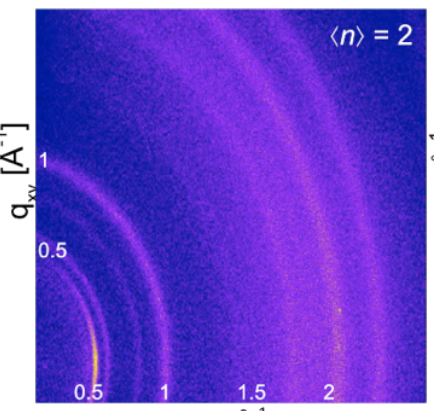

$q_{2}\left[\AA^{-1}\right]$

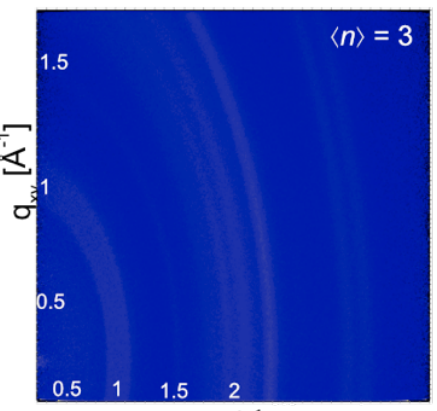

$q_{2}\left[\AA^{-1}\right]$

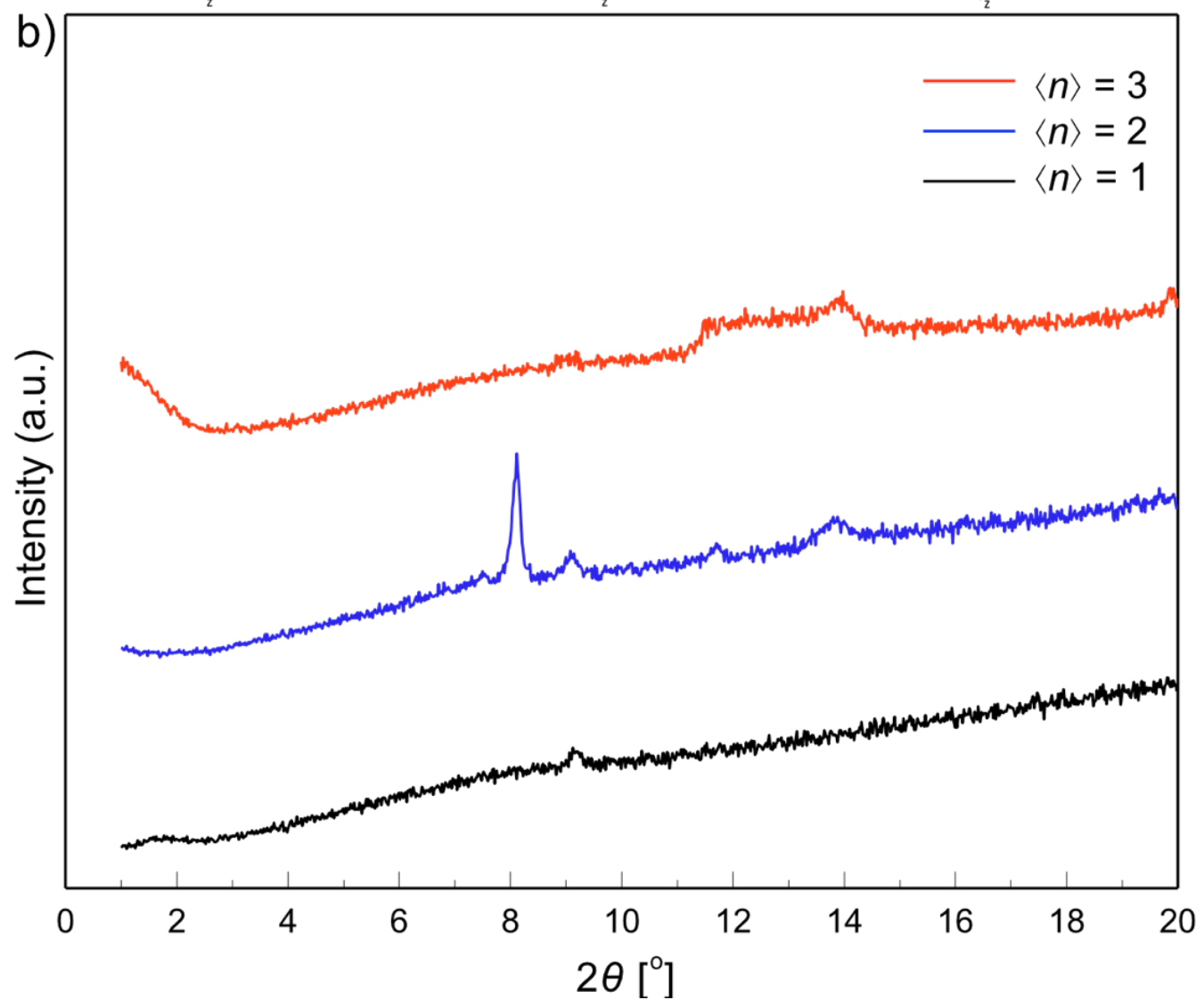

Figure S6. (a) Grazing incidence wide angle X-ray scattering (GIWAXS) data at incidence angles of ca. $2^{\circ}$ and the corresponding (b) XRD patterns for thin films of (NDIEA)FA $A_{n-1} \mathrm{~Pb}_{n} \mathrm{I}_{3 n+1}(\langle n\rangle=1-3)$ compositions on microscope glass. Integrated diffraction patterns (from 2D GIWAXS images) for thin films of (NDIEA)FA $A_{n-1} \mathrm{~Pb}_{n} I_{3 n+1}(\langle n\rangle=1-2)$ compositions on microscope glass slides are provided in the main manuscript (Figure 3c). 


\section{S6. Transient Absorption Spectroscopy}

\section{S6.1. Methods}

Transient absorption spectroscopy measurements were performed on thin-films of perovskite materials of (NDIEA)FA $A_{n-1} \mathrm{~Pb}_{n} \mathrm{I}_{3 \mathrm{n}+1}(\langle n\rangle=1-2)$ compositions along with a neat spacer material. In addition, a reference Dion-Jacobson system based on a (PDMA)PbI ${ }_{4}$ composition compromising electronically inactive 1,4-phenylenedimethanammonium (PDMA) organic spacer was analyzed for comparison.
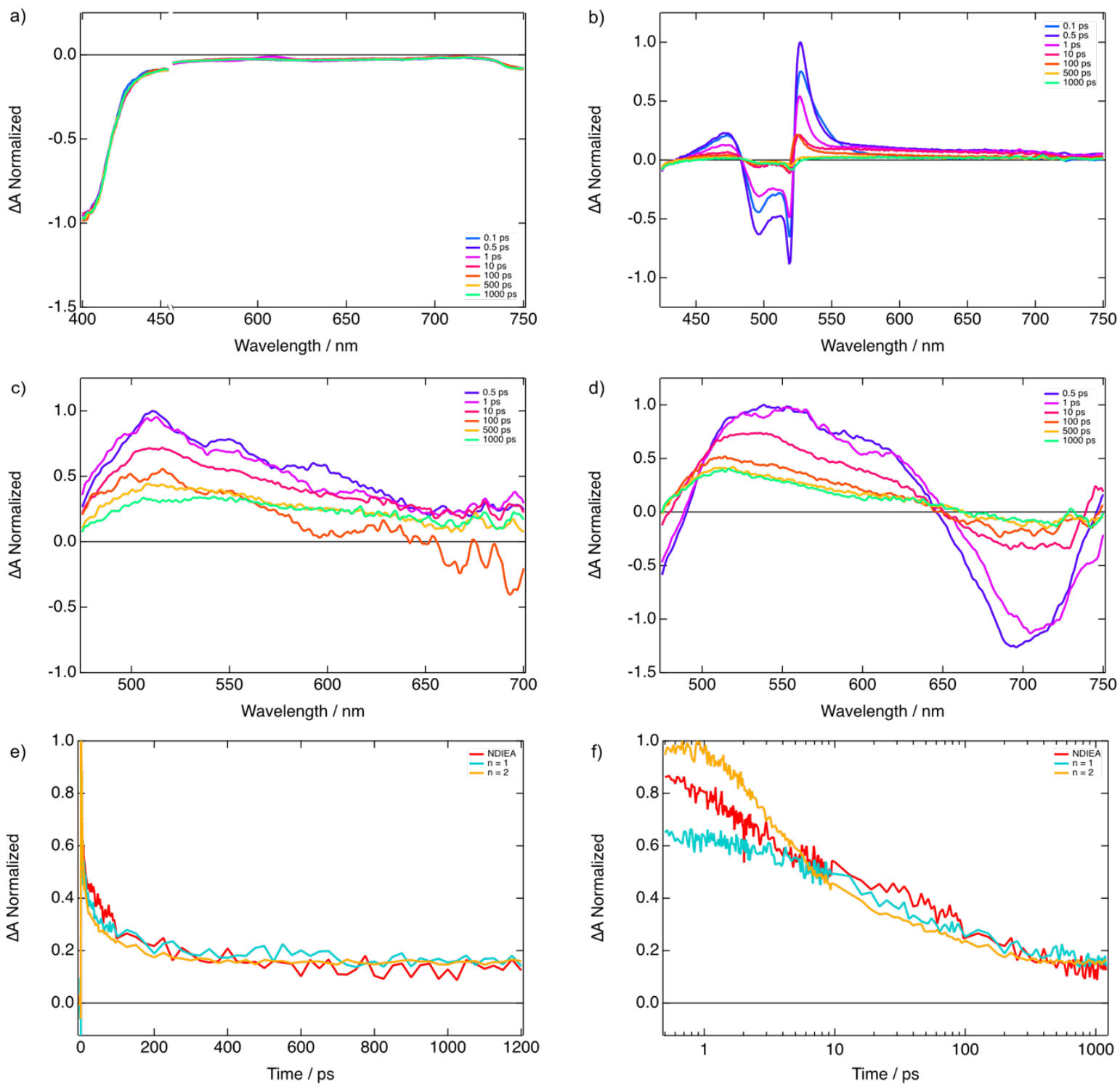

Figure S7. Transient absorption spectra for control thin films of (PDMA) $\mathrm{PbI}_{4}$ composition upon excitation at (a) $510 \mathrm{~nm}$ and (b) $390 \mathrm{~nm}$. The bleach at around $500 \mathrm{~nm}$ observed under b) is characteristic for layered hybrid perovskites of $n=1$ composition. The spectral characteristics upon excitation at $510 \mathrm{~nm}$ shown in a) are different from those of the (NDIEA)FA ${ }_{n-1} \mathrm{~Pb}_{n} \mathrm{I}_{3 \mathrm{n}+1}(\langle n\rangle=1-2)$ compositions shown in the main manuscript in accordance with different electronic properties. (c-d) Transient absorption spectra for thin films of (NDIEA)FA ${ }_{n-1} \mathrm{~Pb}_{n} \mathrm{I}_{3 n+1}(\langle n\rangle=1-2)$ compositions upon excitation at $450 \mathrm{~nm}$. (e-f) Temporal evolution of the main absorption $(530 \mathrm{~nm})$ for $\mathrm{NDIEAI}_{2}$ (red) and (NDIEA)FA $\mathrm{n}_{-}$ ${ }_{1} \mathrm{~Pb}_{n} \mathrm{I}_{3 n+1}(\langle n\rangle=1$ in blue and $\langle n\rangle=2$ in orange), revealing different dynamics as a function of the composition. 

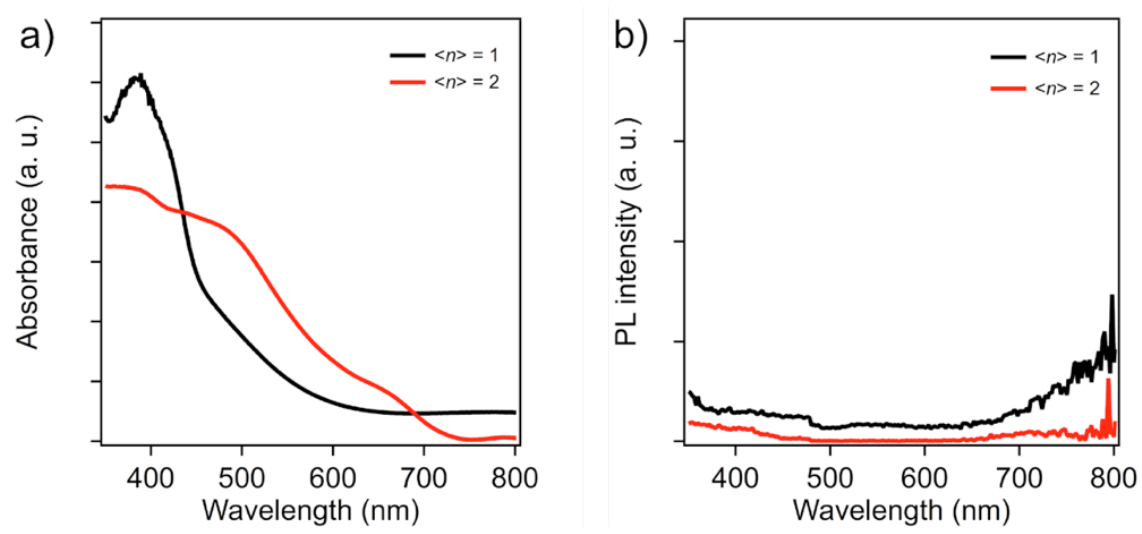

Figure S8. (a) UV-vis absorption and (b) steady-state photoluminescence (PL) spectra of thin films of (NDIEA)FA $\mathrm{F}_{\mathrm{n}-1} \mathrm{~Pb}_{\mathrm{n}} \mathrm{I}_{3 \mathrm{n}+1}(\langle n\rangle=1$ in black and $\langle n\rangle=2$ in red) compositions upon excitation at $420 \mathrm{~nm}$. The preparation of the films is detailed in the Methods section, whereas the concentration of both precursors' solutions for $\langle n\rangle=1-2$ compositions was $0.4 \mathrm{M}$.

\section{S7. Time Resolved Microwave Conductivity Measurements}

\section{S7.1. Methods}

Time-resolved microwave conductivity (TRMC) measurements were used to probe changes in conductivity of layered hybrid perovskites was probed by using high frequency microwaves after the excitation by either high energy electron pulse or a laser. ${ }^{[21-22]}$ The generated free charge carriers absorb part of the microwave power and the fraction of the incoming microwave power absorbed by the sample $(\Delta G)$ is proportional to the change in conductivity of the material $(\Delta \sigma)$, which is defined as the product of charge mobility $(\mu)$ and quantum yield of free charge carrier formation $(\varphi)$. Therefore, from the maximum change in conductivity $\left(\Delta \sigma_{\max }\right)$, mobility $(\mu)$ and quantum yield of free charge carrier formation $(\varphi)$ can be obtained. The relative mobility of charge carriers was estimated by pulse-radiolysis TRMC. TRMC upon laser photoexcitation under conditions specified in the corresponding figure captions was used to analyze thin films of approximately $200 \mathrm{~nm}$ thickness of the layered perovskite materials based on different composition $(\langle n\rangle=1-3)$ as reported (Figure S9).
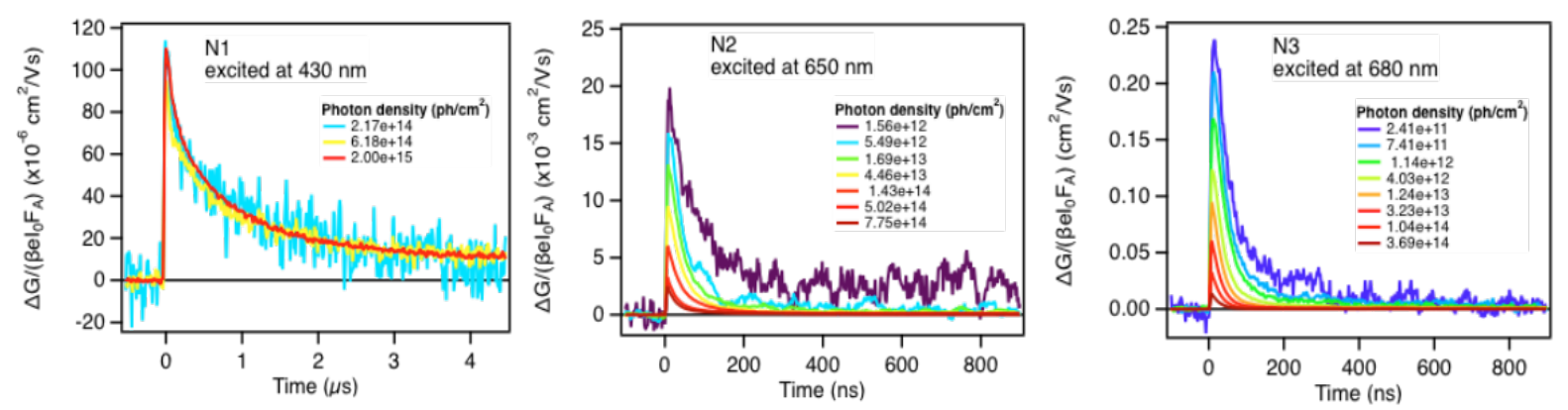

Figure S9. Evolution of photoconductivity over time upon excitation of different perovskite compositions $(\langle n\rangle)$ with various photon intensities $\left(\mathrm{cm}^{-2}\right)$ at $293 \mathrm{~K}$ for $\langle n\rangle=1$ (excitation at $430 \mathrm{~nm}$ ), $\langle n\rangle=2$ (excitation at $650 \mathrm{~nm}$ ), and $\langle n\rangle=3$ (excitation at $680 \mathrm{~nm}$ ) compositions. 


\section{S8. Photovoltaic Performance}

\section{S8.1. Materials}

Commercial materials were used in the process: titanium diisopropoxide bis(acetylacetonate) (75 $\mathrm{wt} \%$ in isopropanol, Sigma-Aldrich); anhydrous ethanol (99.5\%, Fischer Scientific); $\mathrm{TiO}_{2}$ paste (Dyesol 30 NR-D); tin(IV) oxide colloidal dispersion (15\% in water, Alfa Aesar); nickel nitrate hexahydrate $\left(\mathrm{Ni}\left(\mathrm{NO}_{3}\right)_{2} \cdot 6 \mathrm{H}_{2} \mathrm{O}, 99.99 \%\right.$, Sigma Aldrich); 2- methoxyethanol (99\%, Roth); [6,6]-Phenyl-C61-butyric acid methyl ester ( $\mathrm{PC}_{60} \mathrm{BM}$, Sigma Aldrich); chlorobenzene (99.8\%, ACROS); bathocuproine (98\%, TCI); Spiro-OMeTAD (99\%); lithium bis(trifluoro-methylsulphonyl)imide (Li-TFSI, 99.95\%, Sigma Aldrich); 4-tert-butylpyridine (4- $t \mathrm{BP}, 96 \%$, Sigma-Aldrich); lead iodide $\left(\mathrm{PbI}_{2}, 99.9985 \%\right.$, Alfa Aesar); formamidinium iodide (FAI, 398\%, Greatcellsolar); methylammonium iodide (MAI, 398\%, Greatcellsolar); methylammonium chloride (MACl, 99\%, Dyenamo); dimethylformamide (DMF, 99.8\%, Acros); dimethyl sulfoxide (DMSO, 99.7\%, Acros).

\section{S8.2. Methods}

Compact blocking $\mathrm{TiO}_{2}$ layer (c-TiO $)$ : A ca. $40 \mathrm{~nm}$-thick $\mathrm{TiO}_{2}$ compact layer $\left(\mathrm{c}-\mathrm{TiO}_{2}\right)$ was deposited by spray pyrolysis with a precursor solution of titanium diisopropoxide bis(acetylacetonate) (75 wt $\%$ in isopropanol, Sigma-Aldrich) in anhydrous ethanol (99.5\%, Fischer Scientific) at $450{ }^{\circ} \mathrm{C}$. After spraying, the substrates were kept at $450{ }^{\circ} \mathrm{C}$ for $30 \mathrm{~min}$.

Mesoscopic TiO 2 layer $\left(m-\mathrm{TiO}_{2}\right)$ : A suspension of $\mathrm{TiO}_{2}$ paste (Dyesol $\left.30 \mathrm{NR}-\mathrm{D}\right)$ in ethanol $(1: 6 \mathrm{wt} / \mathrm{wt})$ was used to cast a ca. $250 \mathrm{~nm}$-thick mesoporous $\mathrm{TiO}_{2}$ layer by spin coating at $4000 \mathrm{rpm}$ for $20 \mathrm{~s}$. After the spin coating, the solvent was allowed to evaporate on a hot plate at $80^{\circ} \mathrm{C}$ for $10 \mathrm{~min}$ and then sintered at $450{ }^{\circ} \mathrm{C}$ for 30 min under dry air flow.

$\mathrm{SnO}_{2}$ layer: A $15 \%$ tin (IV) oxide colloidal dispersion in water (Alfa Aesar) was further diluted in dionized water $(1: 6 \mathrm{v} / \mathrm{v})$. The dispersion was spin coated over the substrates at $5000 \mathrm{rpm}$ during $25 \mathrm{~s}$ followed by annealing at $160{ }^{\circ} \mathrm{C}$ for $30 \mathrm{~min}$ in ambient air.

NDIEA-treated-SnO $O_{2}$ : A 1 mM NDIEAI 2 solution in DMSO was used to treat the surface of the $\mathrm{SnO}_{2}$ layers in some devices. The solution was spin-coated onto the substrates at $4000 \mathrm{rpm}$ for $20 \mathrm{~s}$ and then the films were heated to $100{ }^{\circ} \mathrm{C}$ for $10 \mathrm{~min}$.

$\mathrm{NiO}$ layer: A $0.1 \mathrm{M} \mathrm{Ni}\left(\mathrm{NO}_{3}\right)_{2} \cdot 6 \mathrm{H}_{2} \mathrm{O}$ (Sigma Aldrich, 99.99\%) in 2-methoxyethanol (Roth, 99\%) was prepared in an argon filled glovebox and stirred overnight at room temperature. The substrates were then spin-coated from solution at $4000 \mathrm{rpm}$ for $20 \mathrm{~s}$ and annealed at $500{ }^{\circ} \mathrm{C}$ for $30 \mathrm{~min}$ in ambient air.

$P C_{60} B M$ : A $22 \mathrm{mM} \mathrm{PC}_{60} \mathrm{BM}$ (Sigma Aldrich) solution in chlorobenzene was deposited on the perovskite substrate by spin-coating at $4000 \mathrm{rpm}$ for $30 \mathrm{~s}$. A heat treatment was carried out at $100{ }^{\circ} \mathrm{C}$ for $10 \mathrm{~min}$ in dry air.

Bathocuproine (BCP): A bathocuproine (TCI, $98.0 \%)$ solution $(0.5 \mathrm{mg} / 1 \mathrm{~mL}$ ethanol) was deposited on top of $\mathrm{PC}_{60} \mathrm{BM}$ by spin-coating at $6000 \mathrm{rpm}$ for $20 \mathrm{~s}$ in dry air.

Spiro-OMeTAD: A solution of Spiro-OMeTAD $(73.5 \mathrm{mM})$ in chlorobenzene with Li-TFSI $(37 \mathrm{mM})$ and $4-t \mathrm{BP}(0.24 \mathrm{M})$ was casted over the perovskite by spin-coating at $4000 \mathrm{rpm}$ for $20 \mathrm{~s}$ in dry air.

(NDIEA)FA ${ }_{2} \mathrm{~Pb}_{3} I_{7}$ ( $n=3$ system): A solution of $1.2 \mathrm{M} \mathrm{PbI}_{2}$ (Alfa Aesar), $0.8 \mathrm{M} \mathrm{FAI} \mathrm{(Greatcell)} \mathrm{and}$ $0.4 \mathrm{M}$ NDI in DMF/DMSO (4:1 v/v) was casted by spin-coating at $5000 \mathrm{rpm}$ for $20 \mathrm{~s}$ followed by an annealing process at $150^{\circ} \mathrm{C}$ for $20 \mathrm{~min}$ in dry air.

$\mathrm{FAPbI}_{3}$ : We followed a two-step deposition solution process, analogous to the one previously reported, ${ }^{[23]}$ a solution of $1.3 \mathrm{M} \mathrm{PbI}_{2}$ in DMF:DMSO $(9.5: 0.5 \mathrm{v} / \mathrm{v})$ was spin coated at $1500 \mathrm{rpm}$ for $30 \mathrm{~s}$, 
and then annealed at $70{ }^{\circ} \mathrm{C}$ for $1 \mathrm{~min}$ in a dry atmosphere, subsequentially, a solution of FAI:MAI:MACl (60 mg: $8.5 \mathrm{mg}$ : $6 \mathrm{mg}$ in $1 \mathrm{~mL}$ isopropanol) was spin coated at $2000 \mathrm{rpm}$ for $20 \mathrm{~s}$, and was then annealed at $150{ }^{\circ} \mathrm{C}$ for $15 \mathrm{~min}$ in ambient air (of $30-40 \%$ relative humidity).

NDIEA-infiltrated $\mathrm{FAPbI}_{3}\left(\mathrm{FAPbI}_{3}: \mathrm{NDIEAI}_{2}\right)$ : The exact same procedure as for the $\mathrm{FAPbI}_{3}$ films was followed with the only difference being that $1 \mathrm{mM} \mathrm{NDIEAI}_{2}$ was added to the $\mathrm{PbI}_{2}$ solution.

The solar cell devices were prepared over glass substrates covered by fluorine-doped tin oxide (FTO) (Nippon sheet glass $8 \mathrm{~W} \cdot \mathrm{sq}^{-1}$ ). Standard cleaning process was performed of the substrates before film deposition; the substrates were thoroughly brushed with a $10 \%$ Hellmanex (Hellma GmbH) solution and then sequentially sonicated in a 2\% Hellmanex solution, acetone and ethanol for 30, 15 and 10 min, respectively. Additionally, the substrates were treated under UV-Ozone for $15 \mathrm{~min}$ between every layer before the perovskite deposition, with the exception of the p-i-n devices where there was no UV-Ozone treatment on the $\mathrm{NiO}_{\mathrm{x}}$ deposition. The architectures are summarized in Table $\mathrm{S} 3$.

Table S3. Summary of different device architectures employed in this study

\begin{tabular}{|c|c|c|}
\hline \multirow{3}{*}{ 2D } & M1 & n-i-p mesoscopic (Glass/FTO/c-TiO $\left.2 / \mathrm{m}_{-} \mathrm{TiO}_{2} /(\mathrm{NDIEA}) \mathrm{FA}_{2} \mathrm{~Pb}_{3} \mathrm{I}_{7} / \mathrm{Spiro}-\mathrm{OMeTAD}\right)$ \\
\hline & M2 & n-i-p planar (Glass/FTO/c- $\left.-\mathrm{TiO}_{2} / \mathrm{SnO}_{2} /(\mathrm{NDIEA}) \mathrm{FA}_{2} \mathrm{~Pb}_{3} \mathrm{I}_{7} / \mathrm{Spiro}-\mathrm{OMeTAD}\right)$ \\
\hline & M3 & p-i-n planar (Glass/FTO/NiOx //(NDIEA)FA $\left.{ }_{2} \mathrm{~Pb}_{3} \mathrm{I}_{7} / \mathrm{PCBM} / \mathrm{BCP}\right)$ \\
\hline \multirow{2}{*}{ 3D } & M1 & n-i-p planar (Glass/FTO/c- $\mathrm{TiO}_{2} / \mathrm{SnO}_{2} / \mathrm{FAPbI}_{3}: \mathrm{NDI} /$ Spiro-OMeTAD) \\
\hline & M2 & n-i-p planar (Glass/FTO/c-TiO $/ \mathrm{NDIEAI}_{2}$-treated-SnO $2 / \mathrm{FAPbI}_{3} / \mathrm{Spiro}-\mathrm{OMeTAD}$ ) \\
\hline
\end{tabular}

\section{S8.3. Supplementary Data}

Table S4. Summary of average performance metrics for 2D perovskite compositions

\begin{tabular}{|c|c|c|c|c|}
\hline Architecture & $\boldsymbol{V}_{\mathbf{O C}}(\mathbf{V})$ & $\boldsymbol{J}\left(\mathbf{m A ~ \mathbf { ~ m } ^ { - 2 } )}\right.$ & $\mathbf{F F}$ & PCE (\%) \\
\hline M1 & 0.406 & 0.01942 & 0.41 & 0.003 \\
\hline M2 & 0.426 & 0.02425 & 0.42 & 0.004 \\
\hline M2* & 0.458 & 0.11965 & 0.39 & 0.021 \\
\hline M3* & n.a. & 0.04485 & n.a. & n.a. \\
\hline
\end{tabular}

Note that $*$ refers to half the concentration described in the methods section.

Table S5. Summary of average performance metrics for 3D perovskite compositions

\begin{tabular}{|c|c|c|c|c|}
\hline Architecture & $\boldsymbol{V}$ OC (V) & $\boldsymbol{J}\left(\mathbf{m A ~ \mathbf { ~ m } ^ { - 2 } )}\right.$ & FF & PCE (\%) \\
\hline M1 & 0.727 & 8.6 & 0.47 & 2.95 \\
\hline M2 & 0.854 & 22.9 & 0.58 & 11.32 \\
\hline
\end{tabular}
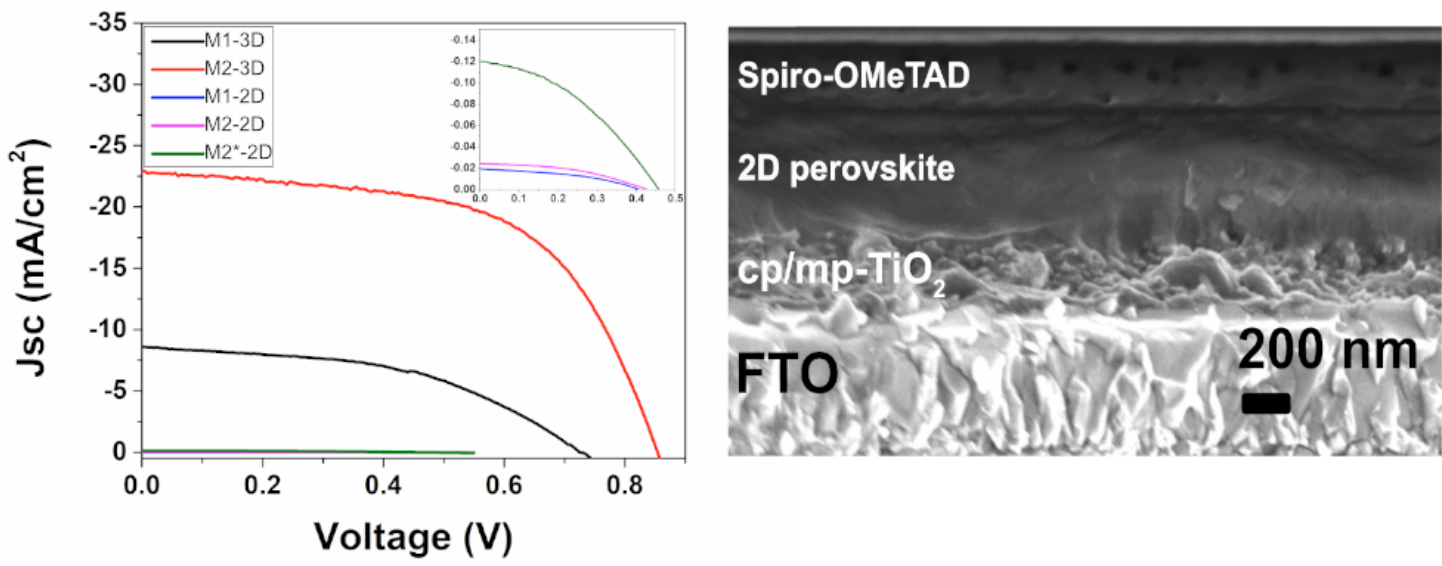

Figure S10. Left: Representative $J-V$ curves for devices prepared by using conditions summarized in Table S3 recorded under standard AM 1.5G illumination at a light intensity of $100 \mathrm{~mW} \mathrm{~cm}^{-2}$ at a scanning rate of $50 \mathrm{mV} \mathrm{s}^{-1}$ under standard AM $1.5 \mathrm{G}$ solar radiation and reverse bias (from $V_{\mathrm{OC}}$ to $J_{\mathrm{SC}}$ ). Right: Cross-sectional SEM image of a representative (NDIEA)FA $\mathrm{Pb}_{3} \mathrm{I}_{10}$-based device. 


\section{References}

[1] Y. Li et al., Bifunctional Organic Spacers for Formamidinium-Based Hybrid Dion-Jacobson TwoDimensional Perovskite Solar Cells. Nano Lett. 19, 150-157 (2019)

[2] J. V. Milić et al., Supramolecular Engineering for Formamidinium-Based Layered 2D Perovskite Solar Cells: Structural Complexity and Dynamics Revealed by Solid-State NMR Spectroscopy. Adv. Energy Mater. 131, 1900284 (2019)

[3] P. Gratia et al., The Many Faces of Mixed Ion Perovskites: Unraveling and Understanding the Crystallization Process, ACS Energy Lett. 12, 2686-2693 (2017)

[4] J-H. Im et al., 6.5\% Efficient Perovskite Quantum-Dot-Sensitized Solar Cell, Nanoscale 3, 40884093 (2011)

[5] D. J. Kubicki et al., Phase Segregation in Cs-, $\mathrm{Rb}$ - and K-Doped Mixed-Cation (MA) $)_{\mathrm{x}}(\mathrm{FA})_{1-\mathrm{x}} \mathrm{PbI}_{3}$ Hybrid Perovskites from Solid-State NMR. J. Am. Chem. Soc. 139, 14173-14180 (2017)

[6] C. Caddeo et al., Collective Molecular Mechanisms in the $\mathrm{CH}_{3} \mathrm{NH}_{3} \mathrm{PbI}_{3}$ Dissolution by Liquid Water. ACS Nano 11, 9183-9190 (2017)

[7] J.-P. Ryckaert et al., Numerical Integration of the Cartesian Equations of Motion of a System with Constraints: Molecular Dynamics of n-Alkanes. J. Comput. Phys. 23, 327-341 (1977)

[8] S. Plimpton, Fast Parallel Algorithms for Short-Range Molecular Dynamics. J. Comput. Phys. 117, $1-19(1995)$

[9] G. Bussi et al., Canonical Sampling Through Velocity Rescaling. J. Chem. Phys. 126, 014101 (2007)

[10] M. Parrinello, and A. Rahman, Polymorphic Transitions in Single Crystals: A New Molecular Dynamics Method. J. Appl. Phys. 52, 7182-7190 (1981)

[11] P. Giannozzi et al., QUANTUM ESPRESSO: A Modular and Open-Source Software Project for Quantum Simulations of Materials. J. Phys: Condens. Matter 21, 395502-395502 (2009)

[12] J. P. Perdew et al., Restoring the Density-Gradient Expansion for Exchange in Solids and Surfaces. Phys. Rev. Lett. 100, 136406-136406 (2008)

[13] (a) N. Ashari-Astani et al., Ruddlesden-Popper Phases of Methylammonium-Based TwoDimensional Perovskites with 5-Ammonium Valeric Acid $\mathrm{AVA}_{2} \mathrm{MA}_{\mathrm{n}-1} \mathrm{~Pb}_{\mathrm{n}} \mathrm{I}_{3 \mathrm{n}+1}$ with $\mathrm{n}=1,2$, and 3. J. Phys. Chem. Lett. 10, 3543-3549 (2019); (b) A.-A. Negar et al., Computational Characterization of the Dependence of Halide Perovskite Effective Masses on Chemical Composition and Structure. J. Phys. Chem. C. 121, 23886-23895 (2017)

[14] A. Q. Alanazi et al., Atomic-Level Microstructure of Efficient Formamidinium-Based Perovskite Solar Cells Stabilized by 5-Ammonium Valeric Acid Iodide Revealed by Multi-Nuclear and TwoDimensional Solid-State NMR. J. Am. Chem. Soc. 141, 17659-17669 (2019)

[15] T. Yanai et al., A New Hybrid Exchange-Correlation Functional Using the Coulomb-Attenuating Method (CAM-B3YLP). Chem. Phys. Lett. 393 51-57 (2004)

[16] C. Adamo and V. Barone, Toward Reliable Density Functional Methods Without Adjustable Parameters: The PBE0 Model. J. Chem. Phys. 110, 6158-6170 (1999)

[17] F. Jahanbakhshi et al., Organic Spacers in 2D Perovskites: General Trends and Structure-Property Relationships from Computational Studies. Helv. Chim. Acta 104, e2000232 (2021)

[18] S. Ahmad et al., Dion-Jacobson Phase 2D Layered Perovskites for Solar cells with Ultrafast Stability, Joule 3, 1-3 (2018)

[19] J.-C. Blancon et al., Extremely Efficient Internal Exciton Dissociation through Edge States in Layered 2D Perovskites, Science 355, 1288-1292 (2017)

[20] S. Meloni et al., Valence and Conduction Band Tuning in Halide Perovskites for Solar Cell Applications' J. Mater. Chem. A 4, 15997-16002 (2016)

[21] R. Herckens et al., Multi-Layered Hybrid Perovskites Templated with Carbazole Derivatives: Optical Properties, Enhanced Moisture Stability and Solar Cell Characteristics. J. Mater. Chem. A. 6, 22899-22908 (2018)

[22] M. C. Gélvez-Rueda et al., Interconversion between Free Charges and Bound Excitons in 2D Hybrid Lead Halide Perovskites. J. Phys. Chem. C. 121, 26566-26574 (2017)

[23] Jiang et al., Planar-Structure Perovskite Solar Cells with Efficiency beyond 21\%. Adv. Mater. 29, $1703852(2017)$ 